Article

\title{
Serious Gaming for Water Systems Planning and Management
}

\author{
Dragan A. Savic *, Mark S. Morley and Mehdi Khoury \\ Centre for Water Systems, University of Exeter, North Park Road, Exeter EX4 4QF, UK; \\ m.s.morley@exeter.ac.uk (M.S.M.); m.khoury@exeter.ac.uk (M.K.) \\ * Correspondence: d.savic@exeter.ac.uk; Tel.: +44-1392-723-637
}

Academic Editors: Zoran Vojinovic and Michael B. Abbott

Received: 22 July 2016; Accepted: 8 October 2016; Published: 14 October 2016

\begin{abstract}
Water systems planning and management share the same roots with gaming, as they rely on concepts in systems analysis, operations research and decision sciences. This paper focuses on Serious Games (those used for purposes other than mere entertainment), with applications in the area of water systems planning and management. A survey of published work on gaming is carried out with particular attention given to applications of Serious Gaming to water systems planning and management. The survey is also used to identify the principal criteria for the classification of Serious Gaming for water related applications, including application areas, goals, number and type of players, user interface, type of simulation model used, realism of the game, performance feedback, progress monitoring and game portability. The review shows that game applications in the water sector can be a valuable tool for making various stakeholders aware of the socio-techno-economic issues related to managing complex water systems. However, the critical review also indicates a gap that exists in the Serious Game application area with the lack of water distribution system games. A conceptually simple, but computationally elaborate new game for water distribution system analysis, design and evaluation (SeGWADE) is presented in this paper. It has a main goal of finding a least-cost design for a well-known benchmark problem, for which the game environment takes the computational and visualisation burden away from the simulation tool and the player. The game has been evaluated in a classroom environment in which a high degree of player engagement with the game was observed, due to its basic game ingredients and activities, i.e., challenge, play and fun. In addition, a clear improvement in learning has been observed in how players attempted to identify solutions that satisfy the pressure criterion with players readily identifying the proximity of the better solutions to the starting, infeasible configuration. Through applications of Serious Gaming such as this, decision makers can learn about the complexity of the water distribution system design problem, experiment safely using a computer model of a real system, understand conflicting objectives (i.e., minimization of cost and satisfaction of minimum pressure) and develop strategies for coping with complexity without being burdened by the limitations of the ICT technology at their disposal.
\end{abstract}

Keywords: serious games; water infrastructure; flood; drought; simulation; visualization; stakeholder engagement; shared vision planning; role playing

\section{Introduction}

Simulation and optimisation tools have been used extensively in water planning and management [1-3]. These computer modelling tools are used in various processes to support rational decision making and have their roots in systems analysis, operations research and decision sciences $[4,5]$. The emergence of the above approaches have historically been linked to the experimental work by applied mathematicians and engineers aimed at supporting military operational planning during the Second World War. 
Gaming has similar roots in systems analysis, operations research and decision sciences. The earliest use of gaming in support of decision making are in war games [5]. They have a long history and originated as devices for planning military operations [6]. The first applications of war gaming can be traced back to political-military exercises conducted by the German and Japanese armed forces prior to the Second World War [5]. The use of gaming in a political-military-security context was subsequently transferred to a non-military context, hence the interest in gaming simulation by, not only computer scientists and game designers, but also decision makers, public policy makers, engineers and scientists. Mayer [5] provides a detailed review of publications related to the development of gaming simulation for purposes such as public policy analysis and planning.

This paper focuses on Serious Games (SG) in the area of water systems planning and management. In other words, it focuses on the complex problems that decision makers (both private and public) face when required to define and evaluate alternative water development plans, technical solutions and management policies. Several definitions are required in order to introduce the basic concepts.

\subsection{Definitions}

\subsubsection{Serious Game}

The notion of serious gaming was introduced by Abt [7], who established how simulation games could be used for education, decision making and for public policy making. Since then, vast amount of literature has been produced on this topic and its various application areas, including educational, science, training, military, government, corporate, healthcare, water management, to name but a few [5,8-10]. Similarly, various definition of a SG exists, but most agree that they are games used for purposes other than mere entertainment. The SG approach offers potentially transformative capabilities to strategic decision-support tools to provide better management of complex water systems compared to purely technical simulation or optimisation methods that have difficulty in capturing the socio-technical challenges of complex systems. The use of serious gaming in education and conflict resolution for policy making is by far the most common in the available literature. As conflicts are often encountered in water systems analysis, a definition of conflict resolution in the context of water systems decision making is offered next.

\subsubsection{Conflict Resolution}

Conflicts often arise in relation to water systems planning and management due to multiple economic, environmental and ecological objectives, as well as due to multitude of conflicting goals and views held by multiple stakeholders. Gleick [11] shows that through history water has been involved in conflict as: a political or military tool, a military target, an object of terrorism, part of a development dispute, and an object of control. Lund and Palmer [12] indicate that examples of these conflicts could include those between the early economic purposes of water development (flood control, agricultural and urban water supply, hydropower, and navigation), newer economic and social purposes (such as recreation and waste assimilation), and recent environmental objectives (such as endangered species). Computer modelling has been used extensively in helping stakeholders resolve various water related conflicts [4]. A concept of Shared Vision Planning [13], which entails engaging stakeholders in developing and experimenting with interactive simulation models, has been an effective way of building consensus—a shared vision.

\subsubsection{Shared Vision Planning}

Palmer et al. [13] define shared vision planning (SVP) as a disciplined planning approach that combines traditional water resources planning methodologies with innovations such as structured public participation and the use of collaborative modelling, resulting in a more complete understanding and an integrative decision support tool. The SVP approach was developed over the years through a number of studies focusing on water systems policy planning and evaluation [13]. Two illustrative 
examples of these include the Lake Ontario-St. Lawrence River SVP Study [14], and the USA National Drought Study SVP Application [15]. It will be shown later that ideas of SVP have been used in a few SG implementations where conflict resolution among different stakeholders is sought.

\subsection{Objectives}

The objectives of this paper are to: (i) carry out a survey of published work on gaming simulation and in particular on illustrative applications of Serious Gaming to water systems planning and management; (ii) identify the principal criteria for the classification of SG for water related applications; and (iii) provide an illustrative example of a Serious Game developed for water distribution system analysis, design and evaluation. These are complementary objectives aimed at informing the reader of the breadth of SG applications, synthesizing their main characteristics and providing an illustration of a new SG application in an area of water resources planning and management that has been missing in the SG literature.

The remainder of the paper is structured as follows. Section 2 presents an introduction to Serious Games for water systems planning and management. Section 3 presents a brief review of Serious Games for water applications and the following Section 4 introduces our proposed classification criteria towards a taxonomy for Water Serious Games. In Section 5, a Serious Game for Water Distribution System Analysis, Design and Evaluation (SeGWADE) is described. Finally, in Section 6, conclusions are drawn and directions for future work are suggested.

\section{Serious Games in Water Systems Planning and Management}

A number of serious games for water systems planning and management have been reported in the literature or can be found online (e.g., [16-18]). This section reviews the representative work developed in this area, focusing on the main characteristics, which will lead to the development of classification criteria adopted later in this paper. The selected SG applications illustrate the breadth of water management subjects addressed and implementation approaches taken, provide examples of best practice and equally limitations of SG implementations, with a view of informing future SG application development and implementation.

Although not specifically developed with water systems management in mind, the SimCity ${ }^{\mathrm{TM}}$ video game series deals with city-building/urban planning decisions and incorporates elements of the urban water cycle into the game. SimCity ${ }^{\mathrm{TM}}$ is a game based on simulation of complex natural, technical and social systems and shares characteristics with Cellular Automata [19] and agent-based modelling [20]. The game represents water supply, treatment and distribution within the city with groundwater as the sole and unlimited source of water. D'Artista and Hellweger [21] criticised the limited representation of the urban hydrologic cycle, giving an example of groundwater pollution having unrealistically short response time. They further state that the functional relation of the various components is also unrealistic, e.g., there is no functional connection between water tower (elevated reservoir) and pump. Gaberdan et al. [20] also point out that the game has a very limited use for the special purpose of urban water management. They go on to propose how SimCity ${ }^{\mathrm{TM}}$ and its simulation engine GlassBox can be extended to include the most important processes of natural urban stormwater management.

A serious game project called Aqua Republica [22], where a virtual world allows participants to develop a river basin and visualise the consequences of their decisions, has been developed by DHI [19]. The aim of the game is to: (1) promote sustainable water resources management by sharing knowledge; (2) raise awareness; and (3) build capacity in some of the most critical issues in water resources management. Aqua Republica combines a game layer with a simulation model, MIKE Hydro Basin [23], for players to experience a role of a manager of an undeveloped river catchment. Chew et al. [24] present a tailored version of the online game for the pilot site in the Middle Olifants region in South Africa. The game starts with the watershed under a hypothetical scenario in year 2000, which implies a certain population, funds, food, energy and an unhealthy ecosystem. During each 
turn, the player has the possibility to make changes in the basin area, while trying to achieve a high basin sustainability score, which is evaluated using the simulation model. While the original Aqua Republica is played over 20 rounds, this version is reduced to 13 rounds to allow enough time for training, but also not to fatigue the participants unduly. The participants included a broad background of specialisation within the fields of water supply, ecology, mining and other industries, local, national and international politics and economy. Although the game has a sophisticated visual interface, it was not seen as a decision-making tool, but an educational aid for capacity building and complexity assessment. The feedback from the participants indicated that the game was not completely intuitive and players needed a few rounds to understand its concept.

Another example of a Serious Game implementation of a fictitious game, but being used for capacity building for transboundary cooperation relating to a real case study, has been given in [25]. The result is the Shariva (Shared River) game aimed at addressing the flood management and mitigation programme of the Mekong River Commission. The game was designed to create awareness and to upgrade knowledge amongst stakeholders and in developing procedures for cooperation in transboundary river basins. The Shariva game is introduced over three workshops (including the introduction to the problem and flood risk management, transboundary water conflict management and water governance, and technical tools to address transboundary issues, respectively). The actual game playing followed after that and involved a total of 28 riparian professionals from Cambodia (6), Lao PDR (7), Thailand (7) and Vietnam (8) coming both from government and non-government institutions. A hydrodynamic simulation model was used to assess the consequences (damage) of various transboundary policy implementations. The outcomes of the game were assessed with respect to two objectives: (1) creating awareness and upgrading knowledge; and (2) the design and review of procedures for addressing and resolving transboundary issues. The first one was assessed using before and after questionnaires, whereas the second one was evaluated using a SWOT (Strengths, Weaknesses, Opportunities and Threats) analysis. The results of the questionnaires showed varied levels of increase in knowledge gained and skills acquired across a number of areas, while the SWOT analysis showed that the key strength of the game is that it can support cooperation aimed at conflict resolution, while the main weakness is considered the amount of time needed to play.

Valkering et al. [26] and Van der Wal et al. [27] use a simulation game as a tool to explore possible future river management dynamics in the Netherlands with a view for developing and assessing policy-relevant climate adaptation pathways. The game deals with a virtual river stretch, representative of many low-lying river stretches in the Rhine delta of the Netherlands. Multiple players are assigned to two stakeholder teams (coalitions) with each team in general agreement among their perspectives on water management. The participants involved in game playing are Dutch water managers and/or academics and takes between two and four hours to play with both problem solving (i.e., minimising negative impacts) and relational aspects (e.g., interaction with other players, consensus building) present in the game. The goal of the game is to manage their river in a sustainable way, which is evaluated via impacts on flooding, drought, nature development and shipping objectives over a period of 10 to 20 years. These objectives are often in conflict with each other, i.e., in attempting to achieve one objective, another objective has to be sacrificed, which requires a conflict resolution approach. The players have a number of common interventions at their disposal ranging from infrastructure enhancements (e.g., dyke broadening, dyke elevation, and river widening), through organisational interventions (e.g., upstream cooperation to reduce peak flows) to flood adaptation (e.g., the flood alarm system enhancements and flood resistant building). The impacts are evaluated using an integrated assessment meta-model based on simple cause-effect relations and response curves [28] considering future climate change and socio-economic development scenarios for the area. The results seem to be presented to the teams by the facilitators. Valkering et al. [26] conclude that based on the analysis of results, it is possible to identify opportunities, no-regret strategies, dead ends and timing of strategy, all of which can be used by policy makers to develop water management roadmaps into the future. It is also interesting to note that the developers introduced an element of surprise into the game by 
providing newspaper headlines (portraying generally unforeseen yet plausible contextual events) and unpredictable occurrence of extremely high or low flows. Van der Wal et al. [27] report that a total of 12 game sessions have been successfully completed.

Stefanska et al. [29] present a similar game for river floodplain management, which is based on the river Tisza reaches, in Hungary. The main differences between this and the game by Valkering et al. [26] are: (i) that there are different roles played by participants (e.g., farmers, local authorities and water authorities) with different spatial influence (of their decisions) and often conflicting objectives (e.g., protection of biodiversity, maximisation of profit and economic efficiency) requiring a conflict resolution strategy; (ii) that in addition to facilitators, there are observers associated with each team of players; and (iii) both a physical game board (showing the river and land parcels at different elevations, which are assigned various types of farming activities, e.g., crop cultivation, animal husbandry, orchard, etc.) and a simple stylised model defining critical relationships and processes are used. The game is played over 6-12 periods (referred to in the game as "years"), in which players test their strategies for their short-term and long-term consequences. The participants involved in game playing ranged from students and academics, through water managers local authorities, to NGOs and professionals. Stefanska et al. [29] report that a total of eight game sessions have been completed in four countries. They conclude that in nearly all the games examined, players failed to organise the process that would allow all actors to express their needs and objectives so that other players would recognise and accommodate them in a common management policy. The authors argue that the failure to take part in a successful problem-solving process is not surprising given the complexity of the problem and limited time for playing the game.

Seibert and Vis [30] present a web-based multi-player game Irrigania, which aims to represent water conflicts among farmers in a simplified way. The game is education-oriented and targeted at class teaching. The game involves a number of villages with farms and farm owners cultivating 10 fields. The players take on the role of individual farmers. The goal for each farmer is to generate the largest net income by choosing the type of irrigation for their fields, i.e., rainfed, river or groundwater irrigation. A simple numerical model is used to calculate the level of resources and income after each round (year) of play. Each game is played over 15 rounds. A simple (numerical) user interface is available, which accesses the database where results for the current year status for the villages and individual farmers can be retrieved and viewed. The authors show how several variants of the game can be played in class by allowing or restricting cooperation among players (students know/don't know who the other farmers in the village are) and sharing complete or incomplete information (students know/don't know the cost and profit system). The authors conclude that despite its simplicity, the game allows interesting patterns to evolve when played in the class.

An interactive learning environment (ILE), WATERSTORY [31] is an example of a digital multi-player game used to provide various stakeholders with opportunities to explore water supply and demand management options on Maui Island. During the game, stakeholders from different fields, including water professionals, experts, businesses, agriculture workers, large landowners, conservation groups, instream flow advocates and the County of Maui, discuss and implement various policy options to analyse their economic, social and environmental impacts across sectors. The System Dynamics model, which uses precipitation as the main inflow for both the surface water and groundwater stocks, is developed to provide information on performance of implemented policies and help resolve any potential conflicts. An interesting feature of the ILE is that it allows players to analyse relationships built into the model and thus increase their understanding of the complex system. This approach is fully compatible with SVP, as it combines traditional water resources planning methodologies (a System Dynamics model) with structured public participation and the use of collaborative modelling (e.g., analysis of relationships built into the model), resulting in a more complete understanding and an integrative decision support tool [13]. The ILE provides two options: simple and advanced simulation modes, which proved useful in addressing audiences with different levels of technical expertise. The authors believe that the ILE succeeded in providing a cohesive and 
stimulating environment in which local stakeholders and the community could explore options and possibly achieve a consensus on current water issues by testing and evaluating the impacts of proposed policies and regulations [31].

Rijcken et al. [32] present a concept design of SimDelta, a framework for an Internet-based interactive simulation model to support decision making for the Dutch Delta Programme [33]. The focus is on the Rhine-Meuse river delta and policy making for flood protection and fresh water supply. The framework involves the development and use of online interactive maps and elements of Serious Gaming to provide Delta Programme stakeholders with insight into the interaction between scenarios, problems and solutions. The authors indicate that a new Delta Model is being developed, with the aim of streamlining existing technical models, connecting different regional models, nesting models of various scales, developing new parts and setting up a data validation procedure. Furthermore, the idea is to use the Internet to more frequently and efficiently present conceptual designs by experts (architects and engineers) to the stakeholders, record their preferences and "crowdsource" corrections, improvements and ideas. All of these elements are clearly aligned with the SVP principles of modelling, structured public participation and more complete understanding of a complex water resources problem. A Serious Game is just an element of a much more complex system being developed. Although the authors state that SimDelta has seven out of nine characteristics of Serious Games, in its present state $[32,33]$ it does not allow various users to interact with each other and there is no indication of the game being actually played and the outcomes of those exercises.

Hill et al. [34] present another collaborative decision-making game aimed at supporting drought preparedness. The Invitational Drought Tournament (IDT) game is played on one of the two river basins that are based on real-world data, but are presented as fictitious in the game to reduce sensitivities. The game is played over the course of a day and has been tested with a number of different participants, ranging from graduate students to water managers and water stakeholders. The game consists of three to four rounds, each representing a drought scenario via climate data (e.g., streamflow, snowpack, precipitation, temperature and water demand), as well as social, economic and environmental impacts. The participants have a number of management options to develop a management plan that is presented to the other teams and referees, who vote for the plan that best reduces environmental, economic and social drought impacts on the river basin. Over time the tournament has evolved to use more objective scoring methods as Wang and Davies [35] report on the System Dynamics model specifically developed for the IDT game to allow easier scoring. The authors indicate that the IDT framework and model helped participants to: (1) understand better complex water resources systems and the trade-offs among conflicting objectives that result from policy choices; (2) improve their understanding of other stakeholders' positions; and (3) interact with one another, prioritise management options and potentially build consensus [35].

A similar approach was also adopted by Rusca et al. [36] in their Ravilla simulation game, whose main aim was to encourage learning about water management on the case study of the fictitious Ra Basin. The game is played by UNESCO-IHE students and consists of four phases: (1) situation analysis (data presented to participants); (2) management option selection; (3) simulation model application; and (4) analysis of results and the preparation for the consecutive rounds of the game. Interestingly, the authors also posit a suggestion about the use of computers in the game that is not shared by other water management and game proponents. They state that, although the computer-based model plays an important role in translating decisions by the players to consequences, the model should not become the focal point of the game and the use of the computer should be limited to a minimum [36]. Therefore, in the Ravilla game, the use of the computer to run the model is limited to the facilitator.

The above references show that Serious Games have been applied to the water sector, demonstrating that they are valuable tools for making various stakeholders aware of the socio-techno-economic issues related to managing complex water systems. The increasing number of references appearing in the last five years also indicates that Serious Games are something water researchers and practitioners are becoming aware of and are starting to embrace. Although the number 
of potential SG applications that can be included in the survey is large, we have limited ourselves to the references that have appeared in scientific/professional literature and provide enough detail for further analysis. In the following section, a set of classification criteria is presented to better characterise the type and main features of the reviewed games and provide a structure for the critical analysis of SG applications. Although not all classification information was available in the each of the selected references, the main criteria are clearly distinguishable.

\section{Toward Classification of Serious Games for Water Applications}

Based on the selected literature analysis, the following are the main criteria for the classification of Serious Games for the water sector applications:

"Application area" is the water system domain to which a game can be applied. A number of application domains can be identified but, broadly, two can be distinguished: (1) river basin management; and (2) urban water management. By far, most Serious Game applications are devoted to river basin (or parts of it) management, including integrated water resource management, irrigation, flooding, droughts and / or transboundary issues with or without climate change and socio-economic development scenarios being considered [10,24,29-31,34-36]. On the other hand, urban water management is not a domain studied in many games, which may be an opportunity for further development [21], e.g., introducing better representation of the water cycle, involving policy decisions on the balance between green and grey infrastructure, the impact of urban creep on flood risk in urban areas, water resource management in cities of the future, to name but a few.

"Goal of the game" is the primary aim or outcome of the game. Quite a few of the games reviewed do not have a specific goal to achieve, but aim for the players to develop knowledge and skills, raise awareness of complex issues in water management and develop a collaborative atmosphere for various stakeholders to participate in the decision making process and develop a shared vision of the problem being considered [23,24,31,36]. However, some games like Irrigania [30] have a specific goal, e.g., for each player (farmer) to generate the largest net income, or in the Invitational Drought Tournament, where goals are set by an expert technical committee, to come as close as possible to the management goals [34].

"Initialisation of the game" is related to how the game starts and how the players are introduced to the problem at hand. Some games do not require any facilitators, as from the start the players are learning by playing, e.g., SimCity ${ }^{\mathrm{TM}}$. However, a majority of complex games require facilitation at the beginning or throughout the entire process $[24,26,27,29-31,34,36]$, while some of them require elaborate introductory workshops to explain the problem [25]. The progress of the game can be influenced by the workshops and the involvement of facilitators, who can engage simply by running the models used to assess a solution proposed by players [36], or even act as "referees", who can answer questions about management strategies or game rules and assist with scoring at the end of the game [34].

"Number and type of players" is the number of stakeholders playing the game. Multi-player games are more common, which is understandable considering the application area usually involves a river basin or parts of it where a number of stakeholders exist. This also means that players can take a different role to play and are usually collocated while required to cooperate or compete to achieve the goal(s) of the game $[23,30,31,36]$. Facilitators can also be involved in the game by providing technical support or another player's perspective, e.g., the citizen perspective is played by a project-team member in [26]. Single player games are less common [21,24], although many of the multi-player games can be and are easily played in a single-player mode by the players agreeing on the course of action and implementing it. As for the type of players involved, Serious Games could be aimed at a number of stakeholders from different fields, depending on the problem and the aim of the game. These stakeholders may include water professionals, experts, businesses, agriculture workers, large landowners, conservation groups, instream flow advocates, undergraduate or postgraduate students and academics. 
"User interface" is the interface used in the game. Games can be board-based, computer-based or can use a combination of a physical board and a simulation tool with an appropriate Graphical User Interface, e.g., Stefanska et al. [29]. Entirely board-based games are rare nowadays as increasingly computer simulation plays a significant role in serious games for water applications. However, the majority of the games analysed here use simulation tools with facilitators, who are required to present the results of the decisions, to help guide participants in understanding the simulation tool outputs and the game objectives, or to judge the outcome of the game $[23,24,31]$. Some of the interfaces are basic, providing only numerical/tabular output to the players [27,30], whilst some provide a slider/selection buttons for input/actions, and/or behaviour-over-time graphs to compare performance against a benchmark [31,34,35]. A Geographic Information System representation of the space or simplified spatial maps, has also been proposed [10]. It is interesting to note that very few game interfaces take advantage of sophisticated 3D video technology readily available in the videos game industry [24].

"Simulation model used" is a technical tool used to assess and present players with consequences/outcomes of their decisions. The types of tools used for simulation vary markedly from game to game. Some of them rely on Cellular Automata-like rules to represent the dynamics of the game, while the water system is represented as a set of simple functional relationships $[21,28,30]$. At the other end of the complexity spectrum, some games use off-the-shelf professional simulation tools, such as the water allocation model MIKE HYDRO Basin [23], to provide outputs and inform the players about the consequences of their decisions [24] or a number of individual models linked together into the Delta Model [10]. Other research-type tools (e.g., hydrodynamic simulation or System Dynamics models) can also be used $[25,29,31,35]$. This often requires that facilitators record the decisions by the players, input them into the model and feedback the results [26]. The development of the model offers the opportunity for shared-vision modelling and even further, the opportunity for stakeholders to contribute to the model-building process [31].

"Realism of the game" is the level of simplification of the socio-technical-environmental system is included. Most games are implemented as a simplification of reality to avoid real-life sensitivities or to make it easier to understand the complexity of the system being analysed, whilst still representing some real world issues $[25,26,29,30,34-36]$. Some of the games allow the user to influence the level of simplification [31].

"Performance feedback" is related to the capability to provide continuous feedback on the player's performance in the game. This can be instant [30] or may require an intermediary/facilitator to perform evaluation and provide feedback $[24,26,29,36]$.

"Progress monitoring" is the capability of saving intermediate game results for follow up analysis. This is not often addressed by the developers of Serious Games for water system problems. However, this feature can be crucial in assessing the performance and knowledge acquisition of the players.

"Game portability" relates to whether the game is played on-line or off-line and whether it can be played outside the controlled/supervised environment. Off-line games are more common as they do not require complex server handling or the need to accommodate several players playing the same game $[24,25,29,31,34,35]$. Irrigania [30] is one of the few games that are available on-line and can be accessed by anybody who registers with the website provided by the authors. The SimDelta model is also envisaged to be used on-line [10].

The analysis of selected literature shows that, by far, the majority of game applications in the water sector deal with river basin management, allowing complex problems to be analysed in a protected and controlled game environment. Most of the game applications are highly simplified and address conflict resolution among large numbers of stakeholders, but require facilitation by technical experts. The user interfaces are often rudimentary (e.g., behaviour-over-time graphs) providing only limited feedback to the players and do not take advantage of the sophisticated 3D visualisation technology readily available in the video games industry. None of the games analysed indicate whether intermediate steps performed by the players are saved for the analysis of problem-solving strategies. Finally, none 
of the above games are aimed at the technical design of water infrastructure. The following section describes an attempt to address some of the apparent omissions in the games for the water sector by developing a game for water distribution system analysis, design and evaluation.

\section{A Serious Game for WDS Analysis, Design \& Evaluation: SeGWADE}

Drinking Water Distribution Systems (WDS) are designed to deliver water from a source to users in the required quantity, quality and at satisfactory pressure. WDS are complex, spatially organised systems consisting of numerous interconnected assets (e.g., pipes, valves, pumps, reservoirs), which are arranged in nontrivial configurations and interact in complex ways due to the non-linear nature of water flow governing equations [37]. Due to the complexity of WDS design and operational issues, advanced computation and instrumentation tools are needed to improve a water manager's ability to effectively manage distribution systems. These computational advancements include the development of modelling tools that can simulate the hydraulic behaviour of WDS, such as EPANET [38]. While simulation allows trial-and-error approaches to be used in finding a preferred design or operational interventions, optimization can provide an automated way of finding efficient solutions to a particular WDS problem. For example, the topological design and layout of a WDS can be optimized with a view to minimizing the cost of a layout [39] whilst meeting some minimum design constraint, such as the provision of sufficient pressure at each demand node. The SeGWADE (Serious Game for WDS Analysis, Design and Evaluation) game explores the use of simulation in the context of solving a WDS problem and is described using the aforementioned classification criteria.

Application area: The game deals with the rehabilitation of an existing WDS by the optional installation of duplicate pipes in order to alleviate a pressure deficiency.

Goal of the game: The game has a specific goal, which is for the player to find a solution that minimizes the cost of duplicated pipes and satisfy the minimum pressure criterion. The lower is the cost of the solution, the better it is.

Number and type of players: This is a single-player game, although multiple players can play it at the same time. Apart from the elements of gamification (e.g., a leader board), the players do not need to communicate with each other in order to reach a solution. The game is initially aimed at postgraduate-level engineering students.

User interface: The user interface is accessed via the web-browser and is thus compatible with a variety of platforms (e.g., Windows, Linux, iOS and Android). It takes advantage of sophisticated video technology to allow animation, fully interactive manipulation and aesthetically pleasing immersive 3D visualisation (Figures 1 and 2). Users having access to WebGL [40] capabilities can switch between a medium and a high graphic detail mode which is better able to scale in size for rendering large networks. In order to accommodate the gamut of hardware capability that might be experienced on diverse target platforms, the graphic rendering is designed to fall-back to HTML5 Canvas [41] technology in the event that WebGL rendering is unavailable.

Simulation model used: The game uses a hydraulic simulation engine based on EPANET [38], with the added ability to simulate pressure dependent demands [42]. Adopting a pressure-driven model allows more meaningful results to be shown to the user in the event of a pressure-deficient solution being proposed.

Realism of the game: As with all other games, a level of simplification is necessary to study WDS. In this particular example, the case study involves network rehabilitation considering only duplication of individual pipes. However, it is possible using the developed game to manipulate pumps, valves and other system components in a similar fashion. Similarly, the game engine allows other type of WDS problems to be analysed, such as water quality issues [43], pump operations [44], leakage [45,46] and calibration [47], according to the needs of the game.

Performance feedback: The game is designed to provide continuous and instant feedback on the player's performance in the game. When the user changes one or a number of elements and is happy with the configuration of the network then a "Compute New Results" button (Figure 2) is engaged. 
This runs the modified configuration on the server-side hydraulic solver, returns the simulation results and saves that solution under the game history in the game database.

Progress monitoring: The game engine saves all the intermediate game results (for each "Compute New Results" action) in the game database for the follow up analysis. This feature is crucial in assessing the performance toward the best solution and knowledge acquisition and skills of the players.

Game portability: The game is played on-line, but it can also be installed on an individual computer to be played outside the controlled/supervised environment.

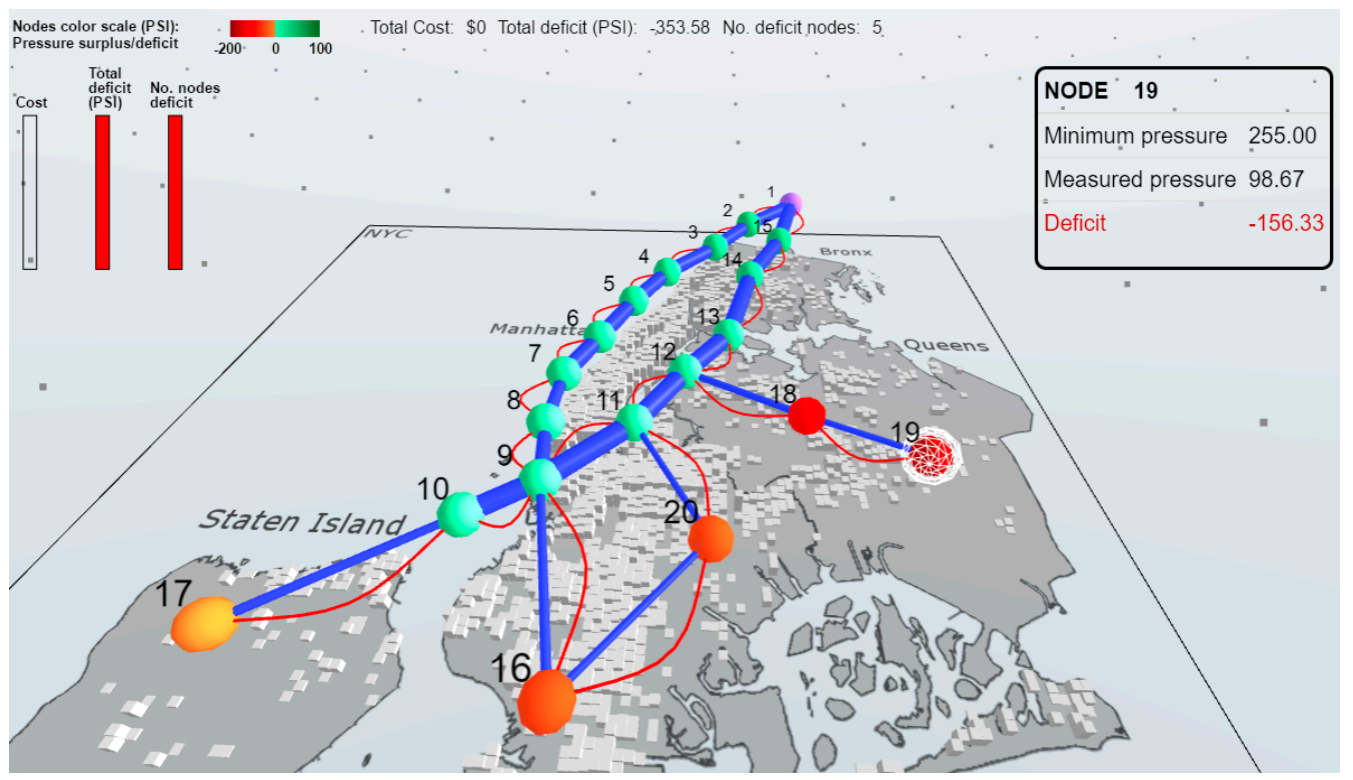

Figure 1. The SeGWADE 3D interface showing the network and an information box (showing deficient pressure at a node).

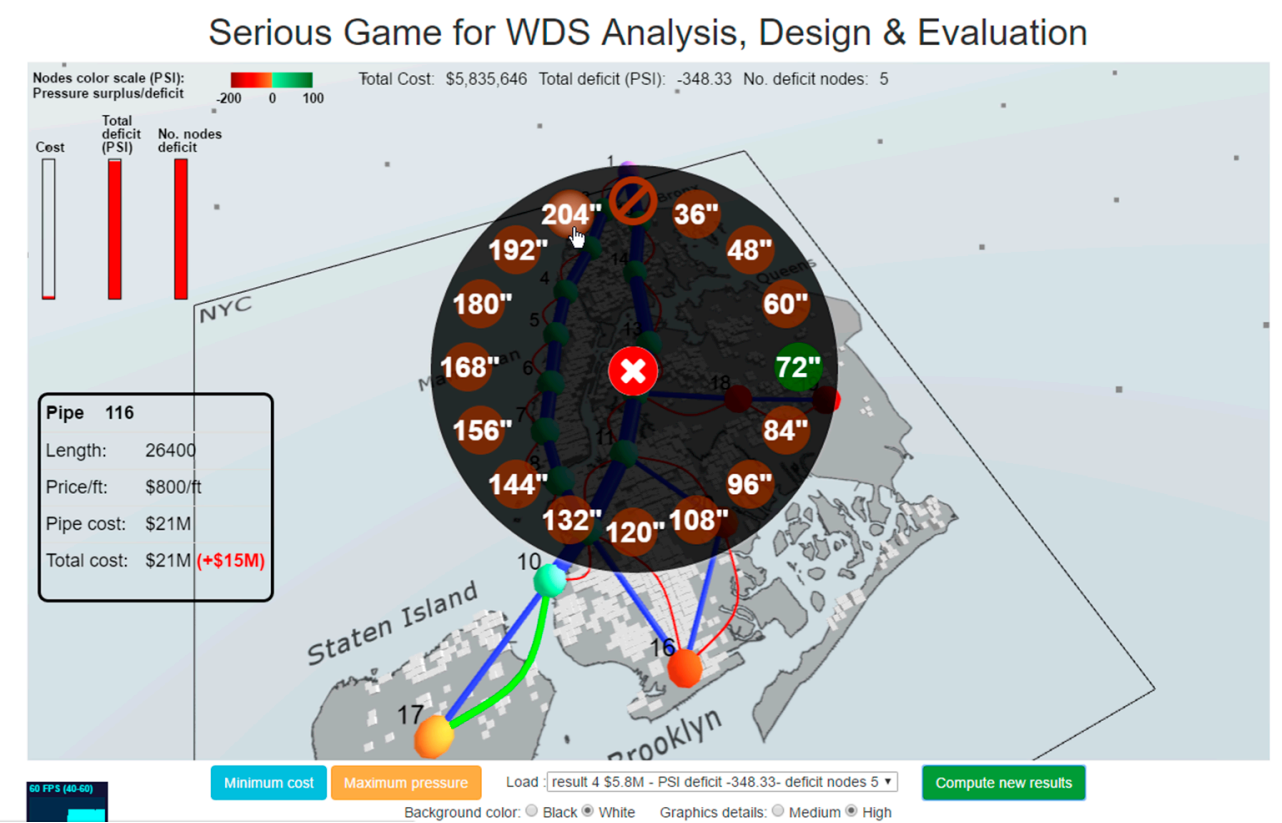

Figure 2. The SeGWADE 3D interface showing a diameter selection wheel with the associate information box for a selected pipe (highlighted in green). 


\section{Case Study}

\subsection{Problem Description and Formulation}

The "New York Tunnels" problem, which was introduced by Schaake and Lai [48] as an illustration of a large-scale optimization problem for the reinforcement of the water supply for New York City, is used as a case study. The tunnels/pipes are of large diameter, ranging from 60 inches $(1.5 \mathrm{~m})$ to 204 inches $(5.2 \mathrm{~m})$. The game starts with the network that is pressure deficient in five nodes (red/orange coloured nodes in Figure 1). In order to solve this problem, each of the 21 pipes in the network can be duplicated with one of 15 commercially available pipe diameters or left as it is (i.e., no new pipe, which is a possible option 16). Despite the apparent simplicity of the problem, this gives a solution space of $16^{21}=1.93 \times 10^{25}$ possible network designs, which is far too many to be checked exhaustively for insufficient pressure, despite the advances of computer power since 1969.

Despite larger networks being used in recent literature, this system has become a favourite benchmark for WDS optimization applications. From the original solution in Schaake and Lai [48] of $\$ 78.1 \mathrm{M}$, the best known solution for the problem has been advanced by, among others, Morgan and Goulter [49] (1985—\$39.23M) and Simpson et al. [39] (1993—\$38.81M). Savic and Walters [50] used the problem to illustrate the sensitivity of such optimization problems to small changes in the coefficients used in calculating the frictional losses observed in the system, demonstrating solutions ranging from $\$ 37.14 \mathrm{M}$ to $\$ 40.45 \mathrm{M}$. The best-known feasible solution (using the latest EPANET software version) of $\$ 38.64 \mathrm{M}$ was obtained using the Ant Colony Simulation approach of Maier et al. [51].

The optimization problem is formulated as:

$$
\begin{gathered}
\text { Minimize } C_{i n f}=f\left(D_{1}, \ldots, D_{N_{l}}\right)=\sum_{j=1}^{N_{l}} C\left(D_{j}, L_{j}\right) \\
C\left(D_{j}, L_{j}\right)=1.1 \cdot D_{j}^{1.24} \cdot L_{j}
\end{gathered}
$$

Subject to:

$$
\begin{gathered}
H_{i} \geq H_{i, \min }, i=1, \ldots, N_{n} \\
D_{j} \in D\left(j=1, \ldots, N_{d}\right)
\end{gathered}
$$

where $C_{\text {inf }}$ is the total cost to be minimized, $N_{l}$ is the number of pipes in the system for which duplication is an option, $C\left(D_{j}, L_{j}\right)$ is the cost (in US dollars) of the $j$ th pipe duplicated with diameter $D_{j}$ (in inches - chosen from a discrete set of available diameters, $D$ ) and length $L_{j}$ (in feet). $H_{i}$ is the pressure head at node $i$ (as computed by the hydraulic solver), $H_{i, \min }$ is the minimum pressure head requirement sufficient to fully satisfy the demand at node $i$ and $N_{n}$ is the number of nodes in the network. $N_{d}$ is the number of decision variables in the optimization.

The WDS consists of two loops and two branches supplied by gravity from a single, fixed-head reservoir. At the start of the game, nodes 16, 17, 18, 19 and 20 fall below the required minimum pressures (shown in red/orange colours relative to the extent of deficiency in Figure 1). The figure illustrates how the network is rendered during the game, with the blue (dark) coloured pipes representing the existing topology of the network with the relative diameters of the pipes clearly visible. The curved pipes represent the duplicate pipes that may be optionally installed in parallel to each of the existing pipes. When no pipe diameter is selected (using the selection wheel in Figure 2) for one of these pipes it is rendered in red and is considered closed in the hydraulic model, whereas green pipes represent open, duplicated pipes. The node representations are colour coded to visually highlight whether they are pressure deficient or not. Nodes shown in green have sufficient pressure, whereas those shaded orange to red are those exhibiting increasing levels of pressure deficiency. 


\subsection{Criteria for Game Evaluation}

An obvious way of evaluating the success of the SeGWADE game is to assess how closely players can get to the best solutions found by competent optimization algorithms. Therefore, the first measurable indicator would be how close a player can get to the best solution reported in the literature, i.e., $\$ 38.64 \mathrm{M}$. Although the additional criteria for judging the success of the game, which include a measure of engagement and the level of knowledge gained by the players throughout the game, could be argued to be even more important, they are, equally, more difficult to measure. In our particular example, the engagement is judged by the number of solutions a player has attempted in the game. Although this is a clearly measurable indicator and it can indicate that well-engaged players get closer to the best solutions found, it has its own disadvantages, as some players could achieve a good solution in a small number of attempts. In addition to achieving a good solution, which provides an indication of knowledge gained in the game, the measure of how much the players have learned will be assessed qualitatively using the knowledge of the decisions (pipe diameters) implemented in the optimized solution [51].

\subsection{Results}

The game was played by a class of 20 MSc students at UNESCO-IHE (Delft, The Netherlands) during one continuous session in June 2016 Figure 3 shows the number of changes made by each of the players and the highest scores they achieved in comparison to the best solution found in the literature ( $\$ 38.64 \mathrm{M}$ - the horizontal dotted red line-note the inverse order axes for the WDS costs). It can be seen that engagement was good, with the majority of students attempting over 100 evaluations of the system and half of them making over 200 changes. From the number of changes attempted within a 4-h long exercise, it is clear that the game maintained the interest of the players. It is also interesting to note that 15 out of 20 players found a solution that was better than $\$ 45 \mathrm{M}$. Only two players have not managed to find a feasible solution to the problem (\#1 and \#13), i.e., a solution that satisfies all minimum pressure requirements.

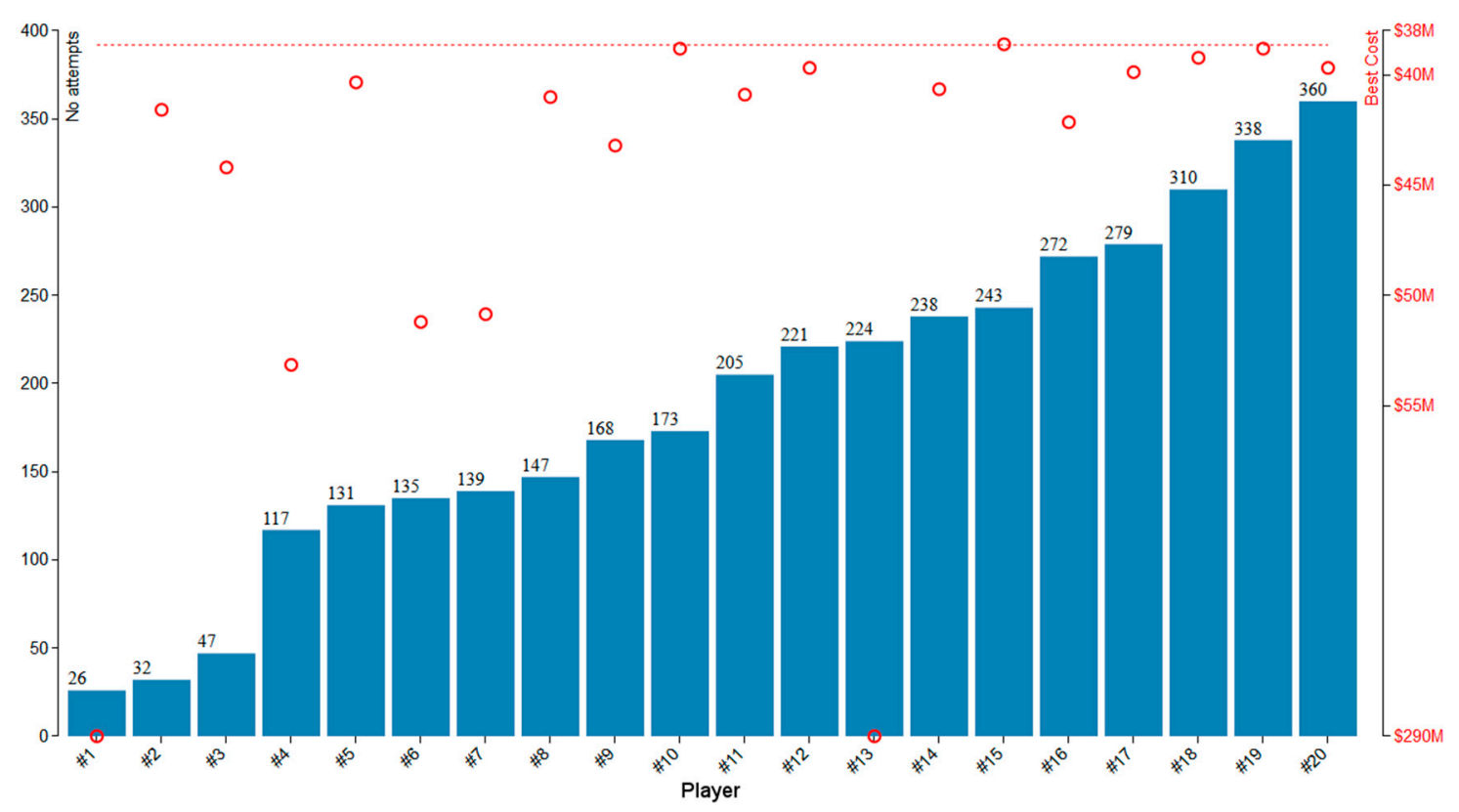

Figure 3. Number of changes made (bar chart) and the best cost attained (red circles) for each of the 20 players.

Figure 4 shows the dynamic performance of the players as the game progressed in terms of their proximity to the best known solution cost of $\$ 38.64 \mathrm{M}$. The three colour lines in this figure represent 
the three highest scoring players in the game (\#10, \#15 and \#19), while the grey lines represent other 17 participants. The majority of players converged upon solutions under $\$ 70 \mathrm{M}$ after making few attempts (i.e., all achieved this in under 50 moves) with most eventually going on to identify solutions better than $\$ 45 \mathrm{M}$. Initially, the players opted to start from the most expensive ( $\$ 290 \mathrm{M})$ and fully compliant solution with all of the duplicate pipes installed, which is indicated by the progress lines touching the bottom of the graph in early attempts. However, it is clear that the players quickly identified that the optimal solution lay closer to the other extent of the problem (i.e., with none of the pipes duplicated) and proceeded to investigate the problem from that starting point. This is evident in the number of solutions oscillating around the best solution $(\$ 38.6 \mathrm{M})$, which requires only six pipes to be duplicated.

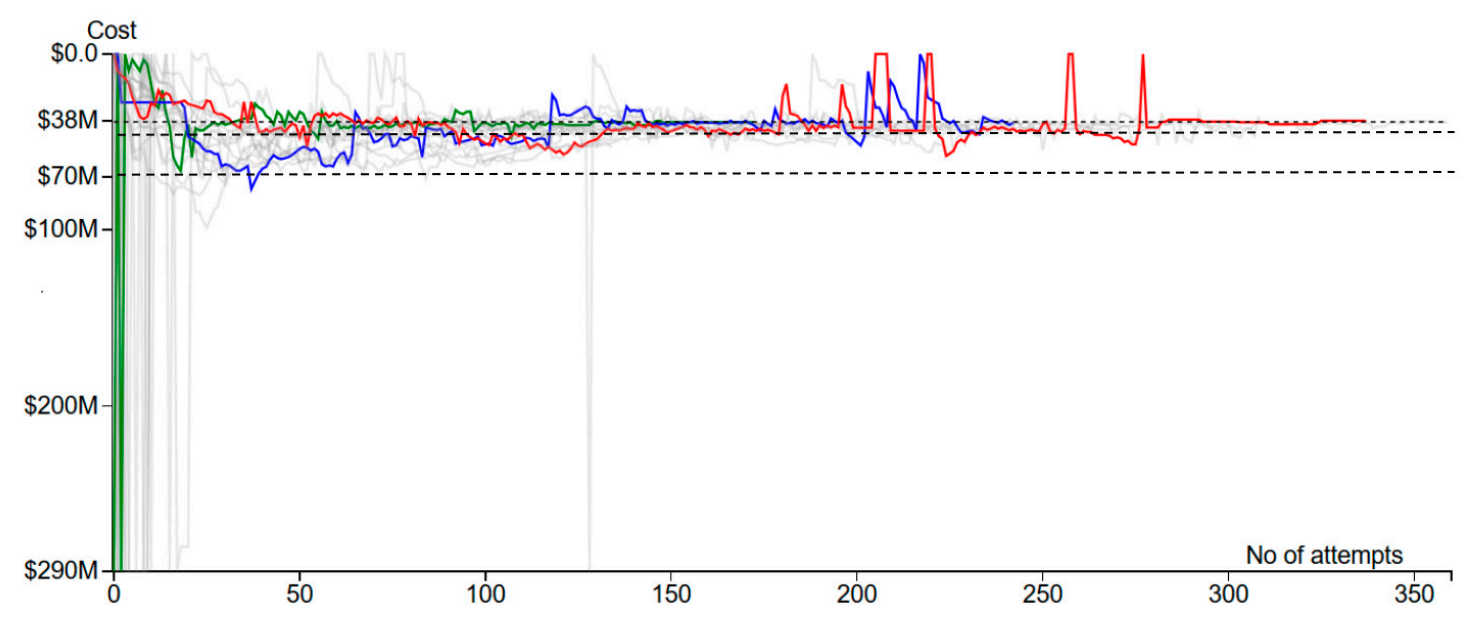

Figure 4. Convergence of players towards the optimal solution.

\section{Conclusions and Future Directions}

This paper provides a number of novel research contributions, namely: (i) a critical analysis of representative SG applications to various water resources analysis and management problems (e.g., flooding, droughts, irrigation, drinking water supply, hydropower, and navigation); (ii) a classification of SG applications in these water management areas, which provides an insight into past research applications and points to future challenges for the research community; and (iii) a new application of SG in water distribution analysis, which is a major area of research and illustrates the complexity of the design/rehab problem for a water distribution system. The Serious Game application presented in the paper also illustrates how a visually-rich hydroinformatics application with an intuitive user interface can help even non-experts (students, in this case) approach a solution to the problem only previously achieved by experts employing sophisticated optimisation tools. Each of these contributions is addressed individually in the following.

The paper reviews the application of Serious Game technology in the water sectors and identifies a number of avenues for improvement. Most game applications in the water sector are primarily educational and deal mostly with river basin management issues (integrated water management), allowing complex problems to be analysed without a specific goal/outcome being identified. The level of simplification in the games is quite high with the aim of informing stakeholders of the complexity of the problem, allowing stakeholders to find ways to resolve conflicts and collaborate in assessing consequences of various policies under the eye of a facilitator (often technical experts). Despite the indication that attention is paid to user interfaces, their visual appeal and functionality, they are basic, e.g., providing behaviour-over-time graphs, whilst not taking advantage of sophisticated 3D visualisation technology readily available in the video games industry. There is also a need to have access to stored intermediate steps performed by the players during the game to allow analysis of 
problem-solving strategies. Finally, none of the above reviewed games are aimed at the technical design of water infrastructure, which is often one of the key tasks in water engineering practice.

A conceptually simple, but computationally elaborate game for water distribution system analysis, design and evaluation is presented in this paper. It has a main goal of finding a least-cost design for a well-known benchmark problem, for which the game environment takes the computational and visualisation burden away from the simulation tool and the player. The game deals with a clearly technical problem, which is a simpler issue to deal with than, for example, river basin management problems where socio-techno-economic complexities dominate. However, the problem is technically complex and require a great deal of expertise and skills to solve. The game engine and user interface are based on the open-source principles (the code is hosted on GITHub [52]) and provide animation, fully interactive manipulation, aesthetically pleasing immersive $3 \mathrm{D}$ visualisation and a database facility to record player performance during the game. This application is new and provides a new, active and personalised way of solving water engineering problems within an immersive and motivating environment capable of providing immediate feedback. Through applications of SG such as this, decision makers can learn about the complexity of the water distribution system design problem, experiment safely using a computer model of a real system, understand conflicting objectives (i.e., minimization of cost and satisfaction of minimum pressure) and develop strategies for coping with complexity without being burdened by the limitations of the ICT technology at their disposal.

The game has an obvious limitation in that it addresses only one of the possible plethora of WDSA problems, i.e., the design of a system. However, it is easily extensible and scalable to involve other WDSA design and operational problems, e.g., water quality issues, pump operations, leakage management and model calibration, and larger networks. Another limitation is that the game is currently only available as a single-player version, which cannot represent fairly various stakeholder aspects, such as for example, the views of a leakage manager vs. that of an asset manager. A multi-player version of the game is currently being developed to address this limitation. It is envisaged that further development could involve multiple objectives and will be undertaken by teams who will be competing in their own right and simultaneously collaborating within teams by allocating different roles to the players on each team such that they represent different stakeholders and have different priorities in terms of the objectives and how they might be achieved.

The SeGWADE game has been evaluated in a classroom environment in which a high degree of player engagement with the game was observed, due to its basic game ingredients and activities, i.e., challenge, play and fun. In addition, a clear improvement in learning has been observed in how players attempted to identify solutions that satisfy the pressure criterion with players readily identifying the proximity of the better solutions to the starting, infeasible configuration.

However, despite the strong belief in the potential of Serious Gaming for the water sector demonstrated by the number of publications in this area appearing over the last five years, there are obvious limitations for their application to solving real water related problems. Apart from the obvious, that they represent a simplified reality of the real world, the use of Serious Games can often be hindered by practical constraints, such as hardware availability and the fact that they may exclude people not used to computing and computers.

Further work can be done to militate against these limitations and to get this particular and other Serious Games developed for the water sector ported to mobile devices as the potential to reach wider audience is much larger due to ubiquitous nature of mobile phones and tablets. Serious Gaming for the water sector is yet to benefit from Virtual Reality and Augmented Reality advancements. They are both new, cutting edge technologies, where Virtual Reality is a computer-generated simulation of a real-life situation or environment (typically achieved by wearing a 3D headset), while Augmented Reality involves layering of computer-generated enhancements atop an existing environment or situation in order to make it more meaningful through interaction. Both have a great potential for serious gaming applications as water systems are complex and large, and do not allow experimentation with a prototype, but only a virtual (computer) representation of it. 
Acknowledgments: The authors would like to acknowledge the funding provided by the UK Engineering and Physical Sciences Research Council, grant EP/M018865/1 (The Nexus Game).

Author Contributions: All authors have contributed to the writing of this paper by performing the review of relevant literature. Dragan A. Savic developed the conceptual idea of a Serious Game for water distribution system design and management, proposed the new classification of Serious Games for water management and wrote the draft of the paper. Mark S. Morley and Mehdi Khoury developed the necessary software and performed the analysis of the outputs of the game. All authors contributed to the editing of the paper as a whole and its revisions.

Conflicts of Interest: The authors declare no conflict of interest.

\section{References}

1. Labadie, J.W. Optimal operation of multireservoir systems: State-of-the-art review. J. Water Resour. Plan. Manag. 2004, 130, 93-111. [CrossRef]

2. Nicklow, J.; Reed, P.; Savic, D.; Dessalegne, T.; Harrell, L.; Chan-Hilton, A.; Karamouz, M.; Minsker, B.; Ostfeld, A.; Singh, A.; et al. State of the art for genetic algorithms and beyond in water resources planning and management. J. Water Resour. Plan. Manag. 2009, 136, 412-432. [CrossRef]

3. Maier, H.R.; Kapelan, Z.; Kasprzyk, J.; Kollat, J.; Matott, L.S.; Cunha, M.C.; Dandy, G.C.; Gibbs, M.S.; Keedwell, E.; Marchi, A.; et al. Evolutionary algorithms and other metaheuristics in water resources: Current status, research challenges and future directions. Environ. Model. Softw. 2014, 62, 271-299. [CrossRef]

4. Loucks, D.P.; van Beek, E.; Stedinger, J.R.; Dijkman, J.P.; Villars, M.T. Water Resources Systems Planning and Management: An Introduction to Methods, Models and Applications; UNESCO: Paris, France, 2005.

5. Mayer, I.S. The gaming of policy and the politics of gaming: A review. Simul. Gaming 2009, 40, 825-862. [CrossRef]

6. Weiner, M.G. An introduction to war games. In Les Choix Economiques: Decisions Sequentielles et Simulation; Rosenstiehl, P., Ghouila-Houri, A., Eds.; Dunod: Paris, France, 1960; pp. 256-279.

7. Abt, C.A. Serious Games; Viking: New York, NY, USA, 1970.

8. Duke, R.D. Origin and evolution of policy simulation: A personal journey. Simul. Gaming 2011, 42, 342-358. [CrossRef]

9. Medema, W.; Furber, A.; Adamowski, J.; Zhou, Q.; Mayer, I. Exploring the Potential Impact of Serious Games on Social Learning and Stakeholder Collaborations for Transboundary Watershed Management of the St. Lawrence River Basin. Water 2016, 8, 175. [CrossRef]

10. Rijcken, T.; Stijnen, J.; Slootjes, N. “SimDelta”-Inquiry into an Internet-Based Interactive Model for Water Infrastructure Development in The Netherlands. Water 2012, 4, 295-320. [CrossRef]

11. Gleick, P. Environment and Security: Water Conflict Chronology-Version 2000. In The World's Water 2000-2001; Gleick, P., Ed.; Island Press: Washington, DC, USA, 2000.

12. Lund, J.R.; Palmer, R.N. Water resource system modeling for conflict resolution. Water Resour. Update 1997, 3, 70-82.

13. Palmer, R.N.; Cardwell, H.E.; Lorie, M.A.; Werick, W. Disciplined planning, structured participation, and collaborative modeling-Applying shared vision planning to water resources. J. Am. Water Resour. Assoc. 2013, 49, 614-628. [CrossRef]

14. International Lake Ontario-St. Lawrence River Study Board. Options for Managing Lake Ontario and St. Lawrence River Water Levels and Flows. Final Report. 2006. Available online: http://www.losl.org/ PDF/report-main-e.pdf (accessed on 1 September 2016).

15. Institute for Water Resources (IWR). Public Involvement and Teaming in Planning. 2002. Available online: http:/ / planning.usace.army.mil/toolbox/library/IWRServer/Public_Involvement_\&_Teaming in_Planning.pdf (accessed on 1 September 2016).

16. Serious Games; Geneva Water Hub: Geneva, Switzerland. Available online: https://www.genevawaterhub. org/resource/serious-games (accessed on 10 October 2016).

17. Games at the World Water Day; Centre for Systems Solutions: Wroclaw, Poland, 2015. Available online: https://watergames.games4sustainability.com/water-games/ (accessed on 10 October 2016).

18. Tygron Engine. 2016. Available online: http:/ / www.tygron.com/ (accessed on 10 October 2016).

19. Wolfram, S. Theory and Applications of Cellular Automata; World Scientific: Singapore, 1986; Volume 1. 
20. Gaberdan, E.; Maier, K.; Söbke, H.; Londong, J. Illustrating decisions to end-users: The case of agent-based simulation for stormwater management. In Proceedings of the Computational Methods in Water Resources 2014 XX. International Conference, University of Stuttgart, Stuttgart, Germany, 10-13 June 2014.

21. D'Artista, B.R.; Hellweger, F.L. Urban hydrology in a computer game? Environ. Model. Softw. 2007, 22, 1679-1684. [CrossRef]

22. Aqua Republica. Available online: http://aquarepublica.com/ (accessed on 10 October 2016).

23. Danish Hydraulic Institute. Mike Hydro Basin: A multipurpose, map based decision support tool for integrated river basin analysis, planning and management-User guide. In Water and Environment; Danish Hydraulic Institute: Hørsholm, Denmark, 2014.

24. Chew, C.; Zabel, A.; Lloyd, G.J.; Gunawardana, I.; Monninkhoff, B. A Serious Gaming Approach for Serious Stakeholder Participation. In Proceedings of the 11th International Conference on Hydroinformatics (HIC2014), New York, NY, USA, 17-21 August 2014. Available online: http:/ /academicworks.cuny.edu/cgi/ viewcontent.cgi?article=1173\&context=cc_conf_hic (accessed on 10 October 2016).

25. Douven, W.; Mul, M.L.; Son, L.; Bakker, N.; Radosevich, G.; Hendriks, A. Games to create awareness and design policies for transboundary cooperation in river basins: Lessons from the shariva game of the Mekong river commission. Water Resour. Manag. 2014, 28, 1431-1447. [CrossRef]

26. Valkering, P.; van der Brugge, R.; Offermans, A.; Haasnoot, M.; Vreugdenhil, H. A perspective-based simulation game to explore future pathways of a water-society system under climate change. Simul. Gaming 2013, 44, 366-390. [CrossRef]

27. Van der Wal, M.M.; de Kraker, J.; Kroeze, C.; Kirschner, P.A.; Valkering, P. Can computer models be used for social learning? A serious game in water management. Environ. Model. Softw. 2016, 75, 119-132. [CrossRef]

28. Haasnoot, M.; Middelkoop, H.; van Beek, E.; van Deursen, W.P.A. A method to develop sustainable water management strategies for an uncertain future. Sustain. Dev. 2011, 19, 369-381. [CrossRef]

29. Stefanska, J.; Magnuszewski, P.; Sendzimir, J.; Romaniuk, P.; Taillieu, T.; Dubel, A.; Flachner, Z.; Balogh, P. A Gaming Exercise to Explore Problem-Solving versus Relational Activities for River Floodplain Management. Environ. Policy Gov. 2011, 21, 454-471. [CrossRef]

30. Seibert, J.; Vis, M.J.P. Irrigania-A web-based game about sharing water resources. Hydrol. Earth Syst. Sci. 2012, 16, 2523-2530. [CrossRef]

31. Bassi, A.M.; de Rego, F.; Harrisson, J.; Lombardi, N. WATERSTORY ILE A Systemic Approach to Solve a Long-Lasting and Far-Reaching Problem. Simul. Gaming 2015, 46, 404-429. [CrossRef]

32. Rijcken, T.; Christopher, D.K. SimDelta global: Towards a standardised interactive model for water infrastructure development. Eur. J. Geogr. 2013, 4. Available online: http:/ /repository.tudelft.nl/islandora/ object/uuid:00654999-6ff3-4f9f-ae50-85e1564cbc26 (accessed on 10 October 2016).

33. Van Alphen, J. The Delta Programme and updated flood risk management policies in The Netherlands. J. Flood Risk Manag. 2015. [CrossRef]

34. Hill, H.; Hadarits, M.; Rieger, R.; Strickert, G.; Davies, E.G.; Strobbe, K.M. The Invitational Drought Tournament: What is it and why is it a useful tool for drought preparedness and adaptation? Weather Clim. Extremes 2014, 3, 107-116. [CrossRef]

35. Wang, K.; Davies, E.G.R. A water resources simulation gaming model for the Invitational Drought Tournament. J. Environ. Manag. 2015, 160, 167-183. [CrossRef] [PubMed]

36. Rusca, M.; Heun, J.; Schwartz, K. Water management simulation games and the construction of knowledge. Hydrol. Earth Syst. Sci. 2012, 16, 2749-2757. [CrossRef]

37. Savic, D.A.; Banyard, J.K. (Eds.) Water Distribution Systems; Thomas Telford Limited: London, UK, 2011.

38. Rossman, L.A. EPANET 2 Users Manual; United States Environmental Protection Agency: Washington, DC, USA, 2000; p. 200.

39. Simpson, A.R.; Murphy, L.J.; Dandy, G.C. Pipe network optimisation using genetic algorithms. In Proceedings of the Specialty Conference of Water Resources Planning and Management Division, American Society of Civil Engineers, Seattle, WA, USA, 1-5 May 1995; pp. 392-395.

40. WebGL: OpenGL ES 2.0 for the Web. Available online: https://www.khronos.org/webgl/ (accessed on 10 October 2016).

41. W3C HTML Canvas 2D Context. Available online: https://www.w3.org/TR/2dcontext/ (accessed on 10 October 2016). 
42. Morley, M.S.; Tricarico, C. Pressure Driven Demand Extension for EPANET (EPANETpdd); Technical Report 2008/02; Centre for Water Systems, University of Exeter: Exeter, UK, 2008; p. 11.

43. Mounce, S.R.; Blokker, E.J.M.; Husband, S.P.; Furnass, W.R.; Schaap, P.G.; Boxall, J.B. Multivariate data mining for estimating the rate of discolouration material accumulation in drinking water distribution systems. J. Hydroinform. 2016, 18, 96-114. [CrossRef]

44. Jung, D.; Lansey, K.E.; Choi, Y.H.; Kim, J.H. Robustness-based optimal pump design and scheduling for water distribution systems. J. Hydroinform. 2016, 18, 500-513. [CrossRef]

45. Giustolisi, O.; Savic, D.; Kapelan, Z. Pressure-driven demand and leakage simulation for water distribution networks. J. Hydraul. Eng. 2008, 134, 626-635. [CrossRef]

46. Sanz, G.; Pérez, R.; Kapelan, Z.; Savic, D. Leak Detection and Localization through Demand Components Calibration. J. Water Resour. Plan. Manag. 2015, 142. Available online: http:/ /dx.doi.org/10.1061/(ASCE) WR.1943-5452.0000592 (accessed on 10 October 2016).

47. Hutton, C.J.; Kapelan, Z.; Vamvakeridou-Lyroudia, L.; Savić, D. Application of formal and informal Bayesian methods for water distribution hydraulic model calibration. J. Water Resour. Plan. Manag. 2013, 140. Available online: http:/ /dx.doi.org/10.1061/(ASCE)WR.1943-5452.0000412 (accessed on 10 October 2016).

48. Schaake, J.; Lai, D. Linear Programming and Dynamic Programming Application of Water Distribution Network Design; Report 116; MIT Press: Cambridge, MA, USA, 1969.

49. Morgan, D.R.; Goulter, I.C. Optimal urban water distribution design. Water Resour. Res. 1985, $21,642-652$. [CrossRef]

50. Savic, D.A.; Walters, G.A. Genetic algorithms for least-cost design of water distribution networks. J. Water Resour. Plan. Manag. 1997, 123, 67-77. [CrossRef]

51. Maier, H.R.; Simpson, A.R.; Zecchin, A.C.; Foong, W.K.; Phang, K.Y.; Seah, H.S.; Chan Lim Tan, C.L. Ant Colony Optimization for Design of Water Distribution Systems. J. Water Resour. Plan. Manag. 2003, 129, 200-209. [CrossRef]

52. Serious Game for WDS Analysis, Design \& Evaluation-Multiplayer Online Serious Game. Available online: https://github.com/gentr1/DWS_serious_game (accessed on 10 October 2016).

(C) 2016 by the authors; licensee MDPI, Basel, Switzerland. This article is an open access article distributed under the terms and conditions of the Creative Commons Attribution (CC-BY) license (http://creativecommons.org/licenses/by/4.0/). 